\title{
General Qualitative Survey on Learning Strategies Employed by Deaf EFL Learners
}

\author{
Poopak Niloofari ${ }^{1}$, Behnam Behfrouz ${ }^{2}$ \\ ${ }^{1}$ Islamic Azad University, South Tehran Branch, Iran \\ ${ }^{2}$ Yabo Foreign Language Education Center, China \\ E-mail address: 1npoopak@yahoo.com, ²b.beh.1986@gmail.com
}

\begin{abstract}
Keywords: Planning; Deaf EFL Learners; Learning Strategies
\end{abstract}
ABSTRACT. This paper, through using relevant literature, covers issues which are effective in planning a strategy by deaf EFL learners who are using learning strategies like cognitive, metacognitive and socio-affective strategies.

\section{INTRODUCTION}

With a careful observation of the environment we find out that the establishment of connection and making communication with the outside world probably is the first and the most important issue which from the outset of every human body's life is with them. For example, two people who are in a quite equal and normal mental and physical condition talk or write to each other in a same language to communicate. But if their languages are different, the manner of communication will change. One of the most elementary ways of communication in such situation is use of signs, or body (visual) languages. And a developed way is the use of common (oral/spoken) languages for communication.

To be familiar with a foreign language, Falk (1987) believes that "it is necessary to examine not only the linguistic properties of the languages involved but also the physical, psychological, and sociological characteristics of the learner. Just as children play an active role in acquiring their native language, so foreign language learners approach their task with established capacities, strategies, physical and cognitive development, goals, attitudes, and motivations all of which interact to affect their success" ( P.353). Therefore, it seems important to consider all effective factors in the learning process. As we know, the audio-visual abilities are the most typical means of communication and conversation. If one of these senses have some or complete deficiency, the other organ would act more powerful than usual. It means that if someone, for example, loses ones visual ability, the hearing ability will enhance to remedy the difficulty of blindness. This process is vice versa in deaf people. A deaf learner, as any human being, has innate abilities and a particular learning style to get and process information, solve problems and make decisions. "Ideally, a foreign (written) language should serve the deaf the same way as it serves members of the hearing society and should, therefore, fulfill cognitive, interactive, and textual functions" (Macurová, 2004, p. 28 ).This group of people even uses different learning strategies and styles during learning process.

For example, they normally experience great difficulty in acquiring spoken languages in contrast to their natural acquisition of signed languages. Without full access to thesounds and intonations of a spoken language, the acquisition process for deaf learners is often difficult and unnatural and happens at a slower rate than for normal learners (Quigley \&King, 1980).

Since this group of language learners has been the minority of every community, less attention has been paid to them and consequently their needs rarely have been obviated. Apart from minority of deaf people as EFL learners, existence of professional teachers, quality educational facilities, and appropriate space and time are instances of some differences between them and normal learners. At the result, access to ideal stage of learning a language requires more efforts and use of more special strategies by deaf EFL learners. Of course, it is evident that this minority group of learners has different needs for education than ordinary learners, do. 
Since learning language is a vital aspect of their life, deaf people from early in life, try to communicate with other people through signs. Therefore, their first language is sign language. Since the foreign language is introduced at the first grade of secondary school in Iran, for upper education all students need to learn it.

On the basis of the statements of one of the supervisors of the disable population organization, (Dr. Gholami, Ghods newspaper, 8/26/2006) the number of deaf people in Iran is about 450,000 , something near $3 \%$ of the population of Iran which is a minority group with specific language and culture. However, the subject of education of such a population is worth to be taken into consideration.

Within the field of education, over the last few decades a gradual but significant shift has taken place, resulting in less emphasis on teachers and teaching and greater stress on learners and learning. The students' greatest need both in and outside the classroom is to learn. In Chastain's (1988) view, people need to know how to learn and they should improve their abilities to control their learning (p.162). He also believes that "the key factor in learning is not what teachers think but what students think, because it is the students' thought processes that determine whether learning is taking place" (p.163). Researchers hypothesize that teaching influences student cognition and that cognition leads to learning. The learners can learn to practice the types of cognitive processes that lead to increased learning.

The core subject of this investigation was to see how deaf learners learn EFL; In other words, this study aimed at recognition and examination of meta-cognitive strategies used by deaf EFL learners which facilitate their process of learning and in the next stage, comparing those strategies with the ordinary EFL learners.

To accomplish this study, first of all the researcher considered the importance of the role of learners and their cognition, then the use of meta-cognitive strategies in the process of foreign language learning.

\section{THEORETICAL BACKGROUND}

\section{Introduction}

In this chapter, the theoretical and empirical basis of the present study will be discussed in detail. First, language learning and teaching and its relevant components will be explained. Then, the different metacognitive strategies used by deaf EFL learners will be investigated in detail.

\section{Language}

Perhaps the most important ability of humankind is the ability to use language. Our language helps us to show our individuality, and it also enables us to become a fully participating member of society and culture. Chastain (1976) views language as "the key that opens the door and allows us to look into the mind of others, to share what they have learned, and feel what they have felt" (P. 56).

We conduct our social lives by means of language. Members of a community or social group express experience, and create their experience through language. They give meaning to it through the mediums such as talking face to face, sending messages or reading a book to convey their meanings. The way in which people use the medium itself creates meanings that are clear and comprehensible to the community they are a member of it (Kramsch, 1998). 
According to Fromkin \& Rodman (1988), there are many characteristics that are common in all human languages some of which can be stated as below:

1. Wherever human exist, language exist.

2. There are no primitive languages; all languages are equally complex and equally capable of expressing any idea.

3. The relationship between the sounds and meaning of spoken languages and between the gestures and meanings of sign languages are for the most part arbitrary.

4. Similar grammatical categories (e.g., noun, verb) are found in all languages.

5. Every language has a way of negating, forming questions, issuing commands, referring to past or future time, and so on.

6. The ability of human beings to acquire, know, and use language is a biologically based ability rooted in the structure of human brain and expressed in different modalities (spoken or signed).

And the most important characteristic of human language is that:

7. Any normal child, born anywhere in the world, of any racial, geographical, social, or economic heritage, is capable of learning any language to which he or she is exposed(P.18).

After all researches about human language especially about sign languages which are used by deaf learners, Fromkin and her associates concluded that "the ability to hear speech sounds is not a necessary condition for the acquisition and use of language" (Fromkin et al. 2007. p. 60-61).

\section{Learning and Language}

By definition learning means acquiring new knowledge or skill and retention of it in mind. Learning comes through focus and practice the new information. It makes some change in behavior and apparently it is an active process because it can occur only when a physical change takes place in the brain. Wittrock (1980) emphasizes on the active nature of the learning process, he states, "The research on the brain and its cognitive processes emphasizes the generative nature of learning and the reciprocal interplay between environmental events and the learner's generative cognitive processes"(p.398). There is a more specialized definition by Kimble \& Garmezy (1963) as follows: "learning is a permanent change in a behavioral tendency and is the result of reinforced practice"(p.133).

In issue of language learning, there is an important distinction between language acquisition and language learning. according to Richards \& Schmidt (2010) "Some theorists use learning to mean a conscious process involving the study of explicit roles of language and monitoring one's performance, and use acquisition to refer to a unconscious process of rule internalization resulting from exposure to comprehensible input when the learners attention is on meaning rather than form (p. 312).

Based on above definition children acquire their first language through unconscious process during which they are unaware of grammatical rules. Children try to acquire language to communicate with the world around. So in order to acquire language they need a source of natural communication. They unconsciously try to imitate and repeat all sounds and words which they hear (babbling and cooing). Little by little they form their language system and get necessary skills for proper and effective use. On the other hand, learning a language is the result of direct instruction of the rules. During learning process, learners consciously learn knowledge of the new language and they are aware of grammatical rules. As Yule (1985) believes that "acquisition is the gradual development of ability of language by using it naturally in communicative situations but learning is more a conscious process of accumulating knowledge of the features such as vocabulary and grammar of a language" (p.163). Studies show that learning second or foreign needs more effort 
because of some factors such capacity constraints of brain due to the existence of first language and its interference in learning another language. Then researchers of language and linguists proposed varieties of theories and methods in learning and teaching a language. For example, in McDonough's (1981) view, the most effective and efficient learning is meaningful learning. He believes that teachers must help learners to find and recognize the most effective strategies for organizing their knowledge into meaningful hierarchies (p.73).

\section{Learning Foreign Languages}

Based on Chastain's (1988) definition "foreign language learning is a situation in which students are studying the language of a foreign country. They normally have little or no direct contact with the language, the people, or the culture; it means that they rarely have opportunities to practice using the language in real language situations" (p.136). Nowadays, learning a language other than our native or first language has become more than just something important. Whether viewed from the financial, political, educational or social aspect, being able to communicate in another language helps to make real connection with people and provides better understanding of our language. One of the most important benefits of learning a foreign language is that the knowledge of language enhances our cognitive and analytical abilities. Obviously, learning a foreign language is tough and involves lots of mental exercise. To being expert in a language; to obtain the necessary skills of that language and to use that knowledge properly, linguists focused on learner and their learning process. Falk (1978) believed that as children play an active role in acquiring their mother tongue, foreign language learners approach their task with established capacities, strategies, physical and cognitive development, goals, attitudes, and motivations all of which interact to affect their success (p. 353).

people normally use different types of strategies in learning a foreign language, such as repeating words over and over, listening attentively, trying to work out the rules of language by forming hypotheses about how it works, guessing the meaning of unknown words, asking a speaker to repeat something and so on (Williams \& Burden, 1997.p.144).

\section{Learning Strategies}

The notion of language learning strategies (LLS) was a shift from teacher's absolute power to learner's responsibility in relation to learning affair. Cohen(1998) explains this innovation as "one potentially beneficial shift in teacher roles is from that of being exclusively the manager, controller and instructor to that of being a change agent-a facilitator of learning, whose role is to help their students to become more independent and more responsible for their own learning. In this role the teachers become partners in the learning process" (p.97).

There are different definitions for learning strategies (LS). Based on O'Malley and Chamot (1990), language learning strategies involve "special thoughts or behaviors that individuals use to help them comprehend, learn, or retain new information" (p.1). Weinstein and Mayer (1986) defined learning strategies as "behaviors and thoughts that a learner engages in during learning and that are intended to influence the learner's encoding process" (p.315).

Rubin (1987) made useful distinction between strategies used by learners. She thought that these strategies help language learning directly and indirectly. She named the first grouplearning strategies. These strategies include both cognitive and metacognitive strategies. Then she classified six main cognitive strategies which directly develop language learning. They are as follows: clarification/verification, guessing/inductive inferencing, deductive reasoning, practice, memorization, and monitoring (p.22-7). Metacognitive strategies in her view are those which used to oversee, regulate or self-direct language learning. The second group of strategies is named communication strategies which used by learner to develop communication with others. Speakers use these types of strategies when they encounter a problem in a communication situation because 
of a lack of perfect knowledge. The third group of strategies is social strategies which refer to the attempts of the learners to enhance their exposure to the language. Strategies in this group involve initiating conversations, watching films, listening, and reading books in the foreign language. Communication strategies and social strategies improve learning indirectly. Rubin (1987) stated that learning strategies "contribute to the development of the language system which the learner constructs and affect learning directly" (p.22). Later on, in 1988, Mayer specified the term LS, as "behaviors of learner that are intended to influence how the learner processes information" (p.11).

In their investigations, Weinstein et al. (1988) pointed that "learning strategies are considered to be any behaviors or thoughts that facilitate encoding in such a way that knowledge integration and retrieval are enhanced. More specifically, these thoughts and behaviors constitute organized plans of action designed to achieve a goal. Examples of learning strategies include actively rehearsing, summarizing, paraphrasing, elaborating, and outlining” (p.291).

Based on O'Malley and Chamot (as cited in Dornyei 2005, p. 168) there are three main types of strategy used by L2learners. The first one is 'metacognitive strategies' which involve planning and thinking about learning, such as planning one's learning, monitoring one's own speech or writing, and evaluating how well one has done. The next one is 'cognitive strategies' involve conscious ways of tackling learning, such as note-taking, resourcing, and elaboration. The last type of strategies is 'social strategies' mean learning by interacting with others, such as working with fellow-students or asking the teacher's help. The type of strategy varies according to the task the students are engaged in.

Tarone (1983) defined LS as the attempts to develop "linguistic and sociolinguistic competence in the target language- to incorporate these into one's interlanguage competence” (p.67).

Later on Oxford (1992) stated that language learning strategies are "specific actions, behaviors, steps, or techniques that students (often intentionally) use to improve their progress in developing L2 skills. She believes that learners by applying these strategies can promote the internalization, storage, retrieval, or use of the new language. In her view strategies are tools by which learners participate in their own learning processes which are needed for developing communicative ability"(p.18).

Cohen (1998) defines language learning strategies as "those processes which are consciously selected by learners and which may result in action taken to enhance the learning or use of a second or foreign language, through the storage, retention, recall, and application of information about that language", and he argued that 'language learning and language use strategies can have a major role in helping shift the responsibility for learning off the shoulders of the teachers and on to those of the learner'(p.4-21). For him, more effective learners intentionally and systematically selected and combined strategies relevant to the language task.

According to the studies of Weinstein et al. (2000), research about 'learning strategy' started at the late 1960s when information processing theories were put into practice in the domain of memory strategies to be used in educational settings. Those days the conception of learner changed from 'active' to 'passive' individual who can direct his or her own learning process. The issue of 'learning strategy' turned into an outstanding subject of research in the area of learning in the 1980s (pp.727-747). We should consider that learning strategies are distinct from learning styles. The term 'learning styles' refers to some general approaches- for example, global or analytic, auditory or visual - that learners use in acquiring a new language or in learning any other subject. These styles are "the overall patterns that give general direction to learning behavior" (Cornett, 1983, p.9). On the other hand, learning strategies are defined as "specific actions, behaviors, steps, or techniques such as seeking out conversation patterns, or giving oneself encouragement to tackle a difficult language task which used by learners to enhance their own learning" (Scarcella\& Oxford, 1992, p. $63)$. 
Learning strategies help learners become more autonomous. Autonomy requires conscious control of one's own learning processes. Learning strategies also enhance self-efficacy, individuals' perception that they can successfully complete a task or series of tasks (Bandura et al., 1963). Major varieties of language learning strategies are cognitive, mnemonic, metacognitive, compensatory (for speaking and writing), affective and social (Carter\& Nunan, 2001).

\section{Different Types of Learning Strategies}

Language learning strategies can be classified according to their efficiencies in various situations. Oxford (1990, p.17) put different learning strategies in six main groups. She defined them as follow:

a) Cognitive strategies which are mental strategies that the learner uses to make sense of learning. They enable the learner to manipulate the language material in direct ways. When manipulating cognitive strategies, the learner is involved in practicing, receiving and sending messages, reasoning, analyzing, note-taking, summarizing, synthesizing, outlining, reorganizing information to develop stronger schemas (knowledge structures), practicing in naturalistic settings, and practicing structures and sounds formally.

b) Metacognitive strategies which are essential for the learner to plan, monitor and evaluate learning. They are employed for managing the learning process. When you concentrate on a subject material you can get it easily. Meta- cognitive strategies involves focusing on one goal, design a learning target, and evaluating yourself. If someone focuses on learning, arranges and planes, and evaluate his learning, we can say he uses meta-cognitive strategies.

c) Memory-related strategies which are used for storage of information. They help learners to link one second/foreign language item with another, but do not necessarily involve deep understanding. Learners are to be given the chance for linking mental images, applying images and sounds, reviewing well and employing action.

d) Compensatory strategies which help the learner make up for missing knowledge. They are important to those who fail to learn language. It helps the learner think of solutions when facing difficulties. Such as guessing from the context in listening and reading, using synonyms and "talking around" the missing word to aid speaking and writing and strictly for speaking, and using gestures or pause words.

e) Affective strategies which are concerned with the learner's emotional needs such as identifying one's mood and anxiety level, talking about feelings, rewarding oneself for good performance, and using deep breathing or positive self-talk. Learners use this strategy to control themselves to have a good condition to learn language. The main effect of this strategy is to reduce anxiety. Then learning will be practiced more quickly.

f) Social strategies which help learner work with others and understand the target culture. Because our relationship between people is important, using this relationship we can complete our knowledge and do whatever we couldn't do by ourselves. They lead to more interaction with the target language through cooperating with others, empathizing with others, asking questions to get verification, asking for clarification of confusing point, asking for help in doing a language task, talking with a native-speaking conversation partner and exploring cultural and social norms.

However, there are other classifications for language learning strategies from different researchers, but two of the more adapted classification offered by Xiaotang\& Min (2000) which the first one is related to the role of those strategies that are effective in learning process such as cognitive strategies, meta-cognitive strategies, affective strategies and communicative strategies. The second one is that according to the areas of language knowledge and language skills, there are strategies for learning pronunciation, grammar, vocabulary and strategies for developing listening, speaking, reading and writing skills (p.35-36). 


\section{The Significance of LLS for Students}

Language learning strategies are those individual and particular means used by language learners which help them to realize, learn and remember and apply new knowledge of language. By use of these strategies learners try to succeed in the complex task of learning a language. If learners use these strategies efficiently, then they can improve their learning process and self -examine their own progress and consequently enhance their learning abilities. According to the Weinstein \&Mayer's view, the major role of strategy use is "to affect the learner's motivational or affective state, or the way in which the learner selects, acquires, organizes, or interacts new knowledge" (1986, P.315).Oxford ( 1990) believes that one of the influential effects of LLS is to make students more responsible and self -directed for their learning. She states that LLSs are "especially important for language learning because they are tools for active, self-directed movement, which is essential for developing communicative competence (p.1). With regard to these definitions, we can deduce that accurate use of LLS mostly results in improved proficiency and through achievement of language skills.

\section{The Role of Strategies in Language Learning Process}

Theoretically learning a second or foreign language seems more difficult than acquiring first language, because of less space in memory span during learning a new language in contrast to learning first language. Therefore, lots of attention is paid to the subject of input and information processing in learning a language. Experiences have proved that successful language learners are those who use different and effective strategies by themselves or by the help of instructors to enhance information processing and fill the gap between new information and existing knowledge. According to Oxford (1990) these strategies can take part in communicative competence of learners, make them to become more self directed and manage their own learning and as a result improve the role of language teachers, Furthermore these strategies help the learner to direct his/herown learning process and also improve the learner's ability to overcome knowledge gaps to continue the communication (p.9).

\section{Cognition and Language Learning}

According to definition of American Heritage Dictionary(as cited in Chastain 1988) cognition means "the mental process or faculty by which knowledge is acquired". Chastainconsiders cognition as "all types of mental processing, such as perception, comprehension, rehearsal, elaboration, retrieval, problem solving, and thinking" ( p.43).

As stated by Chastain (1971) the term 'cognition' "implies proceeding from mental understanding and awareness to practice; from studying a structure to seeing it used in context. In other words, the term 'cognition' implies a conscious application of the 'competence, in the conscious development of "performance' skills" (p.48).

On the other hand, "Learning" is defined by Brown (2000) as "acquiring or getting of knowledge of a subject or a skill by study, experience, or instruction" (p. 7). Another definition for learning is by Kimble and Garmezy (1963) as follows: "learning is relatively permanent change in a behavioral tendency and is the result of reinforced practice" (p.133).

\section{Cognitive Strategies}

Based on O'Malley \& Chamot (1987), the learner interacts with the material to be learned by manipulating it mentally (as in making mental images or relating new information to previously acquired concepts or skills) or physically (as in grouping items to be learned in meaningful categories or taking notes on or making summaries of important information to be remembered).

In Oxford's view (as cited in Williams \&Burden1997), cognitive strategies help the learner to apply the language material in direct ways, e.g., through reasoning, analyzing, note taking, summarizing, synthesizing, outlining, recognizing information to develop stronger schemas (knowledge structures), practicing in naturalistic settings and practicing structures and sounds formally. She also believed that cognitive strategies are the mental strategies that learners use to make sense of their learning. 
Due to different obstacles and difficulties in learning a language, lots of attention is paid to the strategies used by teachers and learners to overcome this incompetency. Bialystok (1978), believed that to be successful, language learners must use different strategies which help them to process language information. In her view, "these strategies are used to enhance information processing when there is a gap between the new information and the learners' existing knowledge. Some of these strategies increase the explicit knowledge of the code to master the rule system of the new language, some others supply the chance of communication in new language, and some strategies cause learners infer meaning from the unfamiliar linguistic knowledge, and the rest of these strategies help to control the processing of language knowledge, this type of strategies is called metacognitive strategy".

\section{Metacognitive Strategies and Learning}

It is clear that any learners need to regulate their thought about the strategy which they use and adjust it based on the situation to which the strategy is being applied. The process of strategy selection and application include the planning, checking, monitoring, selecting, revising, and evaluating of subject at hand.

According to O'Malley and Chamot (1990,1994), metacognitive strategies are actions which one takes to plan for learning, to monitor one's own comprehension and production, or to evaluate the extent to which a learning goal has been reached. In other word, in their definition about these types of strategies, metacognitive strategies can be used by learners before, during and after a task. Learners use metacognitive strategies to plan for a task, to check how the plan is being carried out during task, and evaluate the learning outcomes after task. An investigation about language learning strategy research has provided empirical evidence that the use of metacognitive strategies is essential to the processing of language information. They planed the subject of metacognitive strategy and its subsets in a table. As we see in this table, there are three categories of metacognitive strategies; planning, monitoring and evaluating. Each one has some subcategories under themselves.

Table 2.1. Metacognitive strategy scheme by Chamot \& O’Malley

\begin{tabular}{|c|c|c|c|}
\hline Metacognitive strategy & Strategy name & Strategy description & Strategy definition \\
\hline \multirow[t]{4}{*}{ Planning } & Advance organization & $\begin{array}{l}\text { Preview } \\
\text { Skim } \\
\text { Gist }\end{array}$ & $\begin{array}{l}\text { Previewing the main ideas } \\
\text { and concepts of a text } \\
\text {;identifying the organizing } \\
\text { principle }\end{array}$ \\
\hline & $\begin{array}{l}\text { Organizational } \\
\text { planning }\end{array}$ & Plan what to do & $\begin{array}{l}\text { Planning how to } \\
\text { accomplish the learning } \\
\text { task ;planning the parts } \\
\text { and sequence of ideas to } \\
\text { express }\end{array}$ \\
\hline & Selective attention & $\begin{array}{l}\text { Listen or read selectively } \\
\text { Scan } \\
\text { Find specific information }\end{array}$ & $\begin{array}{l}\text { Attending to key words, } \\
\text { phrases, ideas, linguistic } \\
\text { markers, types of } \\
\text { information }\end{array}$ \\
\hline & Self management & $\begin{array}{l}\text { Plan when, where, and how to } \\
\text { study }\end{array}$ & $\begin{array}{l}\text { Seeking or arranging the } \\
\text { conditions that help one } \\
\text { learn }\end{array}$ \\
\hline \multirow[t]{2}{*}{ Monitoring } & $\begin{array}{l}\text { Monitoring } \\
\text { comprehension }\end{array}$ & $\begin{array}{l}\text { Think while } \\
\text { listening \& reading }\end{array}$ & $\begin{array}{lr}\text { Checking } & \text { one's } \\
\text { comprehension } & \text { during } \\
\text { listening or reading } & \\
\end{array}$ \\
\hline & Monitoring production & $\begin{array}{l}\text { Think while } \\
\text { Speaking \&writing }\end{array}$ & $\begin{array}{l}\text { Checking one's oral or } \\
\text { written production while it } \\
\text { is taking place }\end{array}$ \\
\hline Evaluating & Self- assessment & $\begin{array}{l}\text { Check back } \\
\text { Keep a learning log } \\
\text { Reflecting on what you learned }\end{array}$ & $\begin{array}{l}\text { Judging how well one has } \\
\text { accomplished a learning } \\
\text { task }\end{array}$ \\
\hline
\end{tabular}

(Source: Chamot\& O’Malley, 1994. p.62) 
After years of studies and observation of empirical evidence Chamot\& O'Malley concluded that employing different types of strategies, especially metacognitive strategies, are basic factors in processing language information and language learning. Therefore, the effective use of metacognitive strategy brings about profound learning and improves performance especially among learners who have problem during learning.

\section{Empirical Studies on Language Learning Strategies}

Rebecca oxford is one of the famous researchers in the area of learning strategies. She gathered the results of her empirical investigations in her books. In 1990, she developed a new language learning strategy system, which includes two main classifications: direct strategies and indirect strategies. The first group subdivided into memory, cognitive, and compensation strategies and the second group according to her view, support language learning indirectly is divided into meta-cognitive, affective and social strategies (p.14-15).

Later on in Language Learning Strategies around the World: cross cultural perspectives, issue 13(1996), Oxford mentioned some empirical studies by other researchers, too. As she stated in her book empirical studies of learning strategies of learners revealed that memorization is a strongly preferred strategy among learners (Politzer, undated; Politzer\&McGroarty, 1985; Tyacke\& Mendelsohn, 1986).

\section{Instructional Approaches for Deaf Learners}

There are three types of instructional approaches for communication of deaf learners.

Oral approach focuses on the improvement of speech, speechreading, and listening by the help of amplification. Marschark believes that learning and using oral language improves social integration in a hearing society (Marschark et al., 2002).

Bilingual bicultural approach emphasizes the early use of sign language as the deaf natural language (Fiedler, B.C. 2001). It considers the placement and educational approaches for students who are deaf and hard of hearing. For example a sign language like ASL, be the language of instruction and English be taught through reading and writing and fingerspelling used as an instructional tool. Then English will be used as a second language of these learners. On Marschark view, "sign language can play a positive role in educational, social, and personal development of most deaf children" (Marschark et al., 2002, p.104).

Total communication which stresses on using the learner's preferred mode of communication. This approach is a combination of oral and auditory approaches plus speech reading, sign language, and other manual systems (Fiedler, 2001).

\section{Components of Signs and Signed Languages}

Every natural language has some essential elements and signed languages as other natural languages have some exclusive components. Marschark (2007) classified the most important elements of signed languages as below:

Finger spelling based on Padden's definition (as cited in Marschark2007) "is the use of the manual alphabet for producing one letter at a time and amplifies the comprehension of signs". He also stated that in spoken languages sometimes we may spell a new word when we do not know how to pronounce it; finger spelling performs this function in sign languages to minimize misunderstanding(pp. 189-201). Sometimes when there are no conventional signs for words to better communication finger spelling is used. 
Modification and inflection in Marschark's view (2007) related to the "shape of the hands, place of the hands at which signs are made and movement of the hands". Other distinguishable characteristics of signs are in relation to whether they are made with one hand or two hands, their orientation, or whether they involve a stable "base" hand or not. Changes in the movement, place of articulation, or hand shape of a particular sign can be used to modify the number or tense of assign just as words in English can be modified or inflected by adding particular beginnings or endings (p.74).

Classifiers according to Marschark (2007) are sometimes called poly componential signs. He referred to classifiers as "linguistic units that identify characteristics of their referents". Sign languages use the shape of the hand to create the function of classifiers. The function of these units is like the act of morphemes in spoken languages. Most classifiers are particular hand shapes which have meanings that determined by context. But there are different kinds of classifiers with distinct functions such as entity classifiers, handle classifiers, size and shape classifiers. These units indicate location, motion, manner of movement, distribution, and shape (p.75-76).

Using space in Marschark's view is the most important characteristic of signed languages to show the time and location of the subject of conversation. For example, the space in front of a signer used to show the location of people, objects, and places that are parts of proceeding conversation (p.78).

There are a variety of rules in sign languages, for example in all sign languages, most signs must be made within the signing space, a roughly square area from the top of the head to the waist and about one foot to either side of body. Based on Marschark (2007) sign languages even have their own accents, dialects, and idiosyncratic signs. Signs can be restricted to region, school, or individual families. These differences such as dialectical varieties may cause difficulty in communication between deaf society of different places or cultures, just as spoken language users(p. 73-78).

\section{Lip Seading (Speech Reading)}

Some people believe that lip reading is an art, not a science. It is an extremely complex and difficult practice, which may take years to perfect. Lip-reading defined by Richards \& Schmidt (2010) as a system by which deaf people recognize what a speaker is saying by careful observation of the movements of the lips and face muscles this method is an aid to communication for deaf people (p.344). It is technique of understanding speech by visual means of movement of lips, face and tongue when normal sound is not available. According to the observation of behaviors of some deaf communities by the researcher those who use lip-reading technique, must have a good amount of language knowledge, be familiar with the context, and aware of lip-reading ambiguities. The ability of speech reader to understand what is being spoken through lip reading is influenced by the content of the conversation, too. If the speech reader knows the topic of the conversation, and is familiar with the language that is used, speech reading would be easier. The context of speech reading is another important factor in better realization of the spoken language.

Based on researcher's observations and according to private conversation with some of educated deaf people and their connectors in Tehran, Yazd and Gorgan, the speechreading knowledge and ability to understand spoken language through lip reading is not new but today is used somewhat more than before, as an alternative to sign language. Because authorities believe that making relationship with ordinary people is limited through using sign language and few people know this language, so it is better for deaf people to learn this art - lip reading - to better understand spoken language of hearing people and simultaneously by using sign language and speech reading communicate with others. 


\section{CONCLUSION}

\section{Pedagogical Implications}

Deaf people consider English quite important to feel as equal members of a hearing society that use English as a tool to grasp the world. They appreciate the opportunity to take an English course, interact directly with the teacher and their peers, and show a positive attitude towards the learning process.Since little attention was paidto the subject of foreign language learning by deaf in our country, and regarding to the importance of being familiar with an international language such as English for deaf people and because of the limitation of accessible resources and insufficient numbers of experienced and skillful teachers, different studies in this field seems necessary.

Findings reported in this study pertain to the use of meta-cognitive strategies by the deaf (auditory disabled) EFL learners in learning a new language, and the difference between deaf EFL learners and their ordinary counterparts in the use of meta-cognitive strategies. Through examining the outcomes resulted from this study, the researcher hopedto make a better understanding of the issue of language learning by deaf people for the deaf centers' authorities, teachers, and their parents.

\section{Suggestions for Further Research}

For further research, the researcher recommends that someone who likes to study about deaf learners and their learning process considers following suggestions:

If someone is interested in studying in this area there is a need for more information about the children's perceptions of the languages they are working with and their understanding of differences between them. One must also gather more evidence of the strategies that deaf learners use to learn English. A Comparison between deaf and blind EFL learners is worth to be taken into consideration. The effect of the use of computers and internet by deaf EFL learners on learning a foreign language is another area for further research. In practical terms investigation about mentioned researches may enable learners to provide the knowledge about language that already have and use it more constructively to extend their skills as more successful learners of English as a second language.

\section{References}

[1] Andrews, J.F., Leigh, I.W., \& Weiner, M.T. (2004). Deaf People: Evolving perspectives from psychology, education, and sociology. Boston: Pearson Education.

[2] Bandura, Albert and Walteres, Richard, H. (1963). Social learning and personality development. New York: Holt, Rinehart \& Winston.

[3] Bloomfield, L. (1933). Language and linguistics. New York. Holt.

[4] Bowerman, M., Levinson, S.C. (2001). Language acquisition and conceptual development. Cambridge: Cambridge University Press.

[5] Brown, H.D. (2000). Principles of language learning and teaching ( ${ }^{\text {th }}$ Ed). A Pearson Education Company.

[6] Bialystok, E. (1978). A theoretical model of second language learning: Language learning. 28:69-83.

[7] Caldon, R.,\& Greenberg, M.T.(2003). Social and emotional development of deaf children: family, school, and program effects. In M. Marschark\&P.E. 
[8] Spencer (Eds.), Oxford handbook of deaf studies, language education (pp.177-189). NewYork: Oxford University Press.

[9] Carter, R., Nunan, D. (2001). The Cambridge guide to teaching English to speakers of other languages. Cambridge: Cambridge University Press.

[10] Chamot, A.U., \& O'Malley, J.M. (1994). The CALLA Handbook: implementing the cognitive academic language learning approach. Reading, MA: Addison-Wesley.

[11] Chastain, K. (1971). The development of modern language skills: theory to practice. Philadelphia: The Center for Curriculum Development.

[12] Chastain, K. (1988). Developing second-language skills theory and practice. New York: Brace Jovanovich Publishers.

[13] Cohen, A. (1998). Strategies in learning and using a second language. Harlow: Addison Wesley.

[14] Cook, V. (1991). Second language learning and language teaching. New York: Chapman and Hall.

[15] Cornett, C. (1983). What you should know about teaching and learning styles. Bloomington, IN: Phi Delta Kappa.

[16] Dornyei, Z (2005). The psychology of the language learner: individual differences in second language acquisition. Lawrence Erlbaum Associates, Publishers Mahwah, New Jersey, London.

[17] Falk, Julia S. (1978). Linguistics and language: A survey of basic concepts and implications. John Wiley \& Sons, Inc.

[18] Fiedler, B.C. (2001). Journal: Teaching Exceptional Children, 34(2), 54-59.council for exceptional children.

[19] Flavel, J.H. (1976). Metacognitive aspects of problem solving. Hillsdale, NJ: Erlbaum.

[20] Fromkin, V \& Rodman, R. (1988).An introduction to language ( $4^{\text {th }}$ Ed). Holt, Rinehart and Winston, Inc. The Dryden Press.

[21] Fromkin, V., Rodman, R., Hyams, N. (2000).An introduction to language ( $8^{\text {th }}$ Ed). Thomson Wadsworth, a part of The Thomson Corporation.

[22] Gass, Susan. M \&Selinker, Larry. (2008). Second language acquisition: An introductory course $\left(3^{\text {rd }}\right.$ Ed). Taylor \& Francis.

[23] Hayes, S.C., Barnes-Holmes, D., \& Roche, B. (2001). Relational frame theory: A post Skinnerian account of human language and cognition. New York: Plenum Press.

[24] Jack C. Richards \& Richard Schmidt. (2010). Longman dictionary of language teaching and applied linguistics $\left(4^{\text {th }} \mathrm{Ed}\right)$. Great Britain.

[25] Kimble, G.A \&Garmezy, N. (1963).Principles of general psychology (2th Ed). New York: The Ronald Press.

[26] Kramsch, C. (1998). Language and culture.Oxford University Press.

[27] Kimble, Gregory A. Garmezy, Norman. (1963). Principles of general psychology. New York: The Ronald Press.

28] Macurová, A. (2004). An introduction to principles of language learning. The Second Prague International Seminar on Teaching English to Deaf and Hardo-fHearing Students at Secondary and Tertiary Level. University, Prague, Czech Republic. Retrieved from http://jc.ff.cuni.cz/mmp/SMP.pdf

[29] Mac Whinney, B. (1997). Second language acquisition and the competition Model. 
[30] Maller, S.J. (2003).Intellectual assessment of deaf people: A critical review of core concepts and issues. In M. Marschark\& P.E. Spencer (Eds.), Oxford handbook of deaf studies, language and education. New York: Oxford University Press.

[31] Marschark, Lepoutre\&Bement (1998). Mouth movement and signed communication. In R. Campbell \& B. Dodd (Eds.), Hearing by eye II: The psychology of speech reading and auditoryvisual speech (pp. 243-264). London: Tylor\& Francis.

[32] Marschark, M., Lang, H.G., \&Albertini, J.A. (2002). Educating Deaf Students: Research into Practice.New York: Oxford University Press.

[33] Marschark, M. (2007). Raising and educating a deaf child: A comprehensive guide to the choices, controversies, and decisions faced by parents and Educators. New York: Oxford University Press.

[34] Mayer, R. 1988. Learning strategies: An overview. In Weinstein, C., E. Gotez, and P. Alexander (Eds.), learning and study strategies: Issues in Assessment, Instruction and Evaluation (p.11-22). New York: Academic Press.

[35] McDonough, S.H. (1981). Psychology in foreign language teaching. London: George Allen and Unwin.

[36] Mole, Judith, Mc Cole \& Vale.(2005). Deaf and multilingual. A practical guide for teaching deaf students in foreign language classes. Brassington, Derbyshire: Direct Learn Service Ltd.

[37] Moores, D.F. (2001). Educating the deaf: psychology, principles, and practices ( ${ }^{\text {rd }} \mathrm{Ed}$ ). Boston: Houghton Mifflin.

[38] O’Malley, J. M., \&Chamot, A. U. (1987). The cognitive academic language learning approach: A bridge to the mainstream. TESOL Quarterly, 21, 227-249.

[39] O’Mally, M.J., \&Chammot, A.U. (1990). Learning strategies in second language acquisition. Cambridge: Cambridge University Press.

[40] Oxford, R.L. (1990). Language learning strategies: What every teacher should know. New York: Newbury House.

[41] Oxford, R. L. (1992-1993). Language learning strategies in a nutshell: Update and ESL suggestions. TESOL Journal, 2(2), 18-22.

[42] Oxford, R.L. (2003). Learning style \& strategies/oxford, GALA.

[43] Padden, C. (2006). Learning to finger spell twice: young signing children's acquisition of finger spelling. In B. Schick, M. Marschark\& P. E. Spencer (Eds.), Advances in the sign language development of deaf children pp. 189-201. New York: Oxford University Press.

[44] Piaget, J., Inhelder, B. (1969). The psychology of the child. New York: Basic Books.

[45] Pupura, James Enos (1997). An analysis of the relationships between test takers' cognitive and metacognitive strategy use and second language test performance: Language learning. Cambridge University Press.

[46] Quigley, S. P., \& King, C. M. (1980). Syntactic performance of hearing impaired and normal hearing individuals. Applied Psycholinguistics, 1, 329-356

[47] Richards, J.C \&Renandya, W.A. (2002). Methodology in language teaching: An anthology of current practice. Cambridge: Cambridge University Press.

[48] Rubin, J. (1987). Learner strategies: Theoretical assumptions: Research history and typology. In A. Wenden and J. Rubin (Eds.), learner strategies and language learning (p.15-29). Englewood Cliffs, NJ: Prentice Hall.

[49] Saussure, Ferdinand de.(1959). Course in general linguistics. New York: philosophical library. 
[50] Scarcella, R \& Oxford, R. (1992). The tapestry of language learning: The individual in the communicative classroom. Boston: Heinle\&Heinle.

[51] Tahmtani, H. (2010). On the Use of Metacognitive Strategies by Iranian EFL Learners in Doing Various Reading Tasks across Different Proficiency Levels.International journal of language studies (IJLS), Vol. 4(1).

[52] Taylor, R.L, Smiley, L.R, Richards, S.B. (2009). Exceptional students: Preparing teachers for the $21^{\text {st }}$ century. New York: McGraw-Hill Company.

[53] Weinstein, C., \& Mayer, R. (1986). The teaching of learning strategies. In M.C.Wittrock (ed.), Handbook of research on teaching (3rd Ed). New York: Macmillan.

[54] Weinstein, C., Gotez, E., and Alexander, P. (1988). Learning and study strategies: issues in assessment, instruction, and evaluation. New York: Academic Press.

[55] William, M., \& Burden, R.L. (1997). Psychology for language teachers: A social constructivist approach. Cambridge Language Teaching Library.

[56] Wittrock, M.C. (1980). Learning and the brain. In M. C. Wittrock (Ed), the brain and psychology. New York: Academic Press. P. 371-403.

[57]Yoshinaga-Itano,C.Journal of Deaf Studies and Deaf Education 8:1 Winter 2003,University of Colorado, Boulder.

[58]Yule, G. (1985). The study of language.Cambridge University Press.

[59] Zapien, C. (1998). Options in Deaf Education- History, Methodologies, and Strategies for Surviving the System.Exceptional parent magazine. 